\title{
Admissible relative errors of the parcel area of a land parcel map base created as a synthesis of individual survey maps
}

\author{
Andrea Barbieri* \\ Carlos López-Vázquez**
}

Received January 15, 2018; accepted July 21, 2018

\begin{abstract}
Today the land parcel map of Uruguay is available as an updated, integrated legacy digital cadastre which planimetric accuracy is not enough to assure geometric interoperability. The creation of a brand new land parcel map is being considered with a procedure yet to be defined but in any case subject to reasonable goals in terms of geometric accuracy. In this paper we have tested a direct procedure in which each parcel is joined to its immediate neighbors until a block is formed. In Uruguay such block will grow until a road, river or similar object is found. The block is manually inserted within the road network, which has absolute coordinates. The rural survey maps (approx. 250 000) are already scanned but they need to be vectorized and edited through scaling, rotation and manual matching to its neighbors. GNSS tracks for roads and highways are available for the whole country, so we could fit the block within them in order to properly register it. The resulting geometric accuracy was evaluated in terms of the relative error in area, which has a normal distribution with a mean $0.10 \%$ and a standard deviation $3.51 \%$, leaving $82.0 \%$ of the parcels with relative area error less than $5 \%$. The planimetric error, crucial to assure interoperability, was $53.79 \mathrm{~m}$ at the $95 \%$ confidence level.
\end{abstract}

* Programa PEDECIBA Geociencias, Uruguay, ORCID: https://orcid.org/0000-00015675-0095, correo electrónico: abarbierid@gmail.com

** Laboratorio LatinGEO IGM+ORT, Facultad de Ingeniería, Universidad ORT, Uruguay, ORCID: http://orcid.org/0000-0002-8444-1510, correos electrónicos:

carloslopez@uni.ort.edu.uy; carlos.lopez@ieee.org 
Key words: Land parcel map, Survey maps, Geometric Interoperability, Positional Accuracy Improvemen.

\section{Resumen}

Actualmente en Uruguay la cartografía base catastral está dada por un parcelario digital integrado y actualizado pero cuyas características geométricas no son adecuadas para que sea interoperable con otras capas de información de alta exactitud. Se está considerando generar una nueva cartografía, para lo que hay que especificar metodología y requerimientos, determinando la exactitud geométrica que es posible y razonable alcanzar para posteriormente exigirla a la hora de la contratación de dicho trabajo. En este trabajo se ensayó el procedimiento de agregar cada parcela con la(s) parcela(s) lindera(s) formando una unidad. Como en Uruguay las áreas públicas no disponen de mensura, el proceso de unión se interrumpe al llegar a una ruta, un curso de agua, etc. Los planos de mensura rurales (del orden de 250 000) están digitalizados pero no vectorizados, por lo cual tras hacerlo se realizó un trabajo de escalado, rotación y eventualmente deformación para luego integrarlo con sus vecinos. Para las rutas y caminos públicos se dispone de trazas GNSS, lo que permitió darle a cada bloque coordenadas absolutas. La exactitud de la cartografía resultante se valoró en términos del error relativo del área de cada parcela, resultando que el error cometido es de distribución normal, con media $0.10 \%$ y desviación estándar 3.51\%, dejando así al $82.0 \%$ de las parcelas con menos del 5\% de error. En términos de error planimétrico, crucial para asegurar la interoperabilidad, el mismo fue de $53.79 \mathrm{~m}$ al $95 \%$ de nivel de confianza.

Palabras clave: Cartografia catastral, Planos de mensura, Interoperabilidad geométrica, Mejora de Exactitud Posicional.

\section{Resumo}

Atualmente no Uruguai a cartografia base cadastral é um parcelário digital integrado e atualizado mas cujas características geométricas não são adequadas para que seja interoperável com outras camadas de informação de alta exatidão. Se está considerando gerar uma nova cartografia, com metodologia e requerimentos a serem definidos, com metas de exatitude geométrica razoáveis a serem alcançadas para posteriormente serem exigidas na hora da contratação de um trabalho. Neste artigo testou-se um procedimento direto no qual cada parcela é unida a seus vizinhos imediatos até que um bloco seja formado. No Uruguai, esse bloco crescerá até que uma estrada, rio ou objeto semelhante seja encontrado. O bloco é inserido manualmente dentro da rede rodoviária, que possui coordenadas absolutas. Os mapas rurais (da ordem de 250 000) estão digitalizados mas não vetorizados, por isso se realizou um trabalho em escalonamento, rotação e eventualmente ajuste para integrá-los com seus vizinhos. Para as rotas e caminhos públicos se dispõe de traços de GNSS, o 
que permitiu dar a cada bloco coordenadas absolutas. A exatitude da cartografia resultante foi avaliada em termos de erro relativo da área de cada parcela, resultando que o erro cometido é de distribuição normal, com média $0.10 \%$ e desvio padrão de $3.51 \%$, deixando assim $82.0 \%$ das parcelas com menos de $5 \%$ de erro. Em termos de erro planimétrico, crucial para assegurar a interoperabilidade, o mesmo foi de 53.79 m para $95 \%$ de nível de confiança.

Palavras chave: Cartografia cadastral, Planos de medição, Interoperabilidade geométrica, Melhora de Exatitude Posicional.

\section{Introduction}

Today Uruguay has an updated, legacy land parcel map under the administration of a single governmental body (National Cadastral Directorate, Dirección Nacional de Catastro, DNC hereinafter) which covers all the country. According to its effects in civil law, the Uruguayan Cadastre is demonstrative because its information is deemed as true and valid, but not necessarily static. In the situation that a mistake is found it is still possible to modify it. The Uruguayan Cadastre is exhaustive, covers all the territory and holds survey maps for all public or private owners. However, it does not include public roads, highways, parks, etc., because they do not have a parcel number.

The Cadastral information is used as a base for tax computations through the property value. In addition it has legal effects, because the owner of each parcel is recorded. The physical characteristics of the parcel are recorded in a survey map, always made by professional surveyors. Although it does not have absolute coordinates it is deemed to be very accurate in terms of its geometry.

The Decree 318/995 states that the survey map is the base for the correct identification of the parcel in the ground while provides legal evidence for its dimensions (in particular its area). The area value on principle is used for tax computations, property values, etc. so its accuracy is taken for granted. Its numerical value arises directly from the computations made using field measurements by the surveyor, and not from the polygon represented in the survey map.

Today DNC organizes the land parcel map base in two sets: one urban and another rural. The original rural land parcel map was built over polyester through a photo mosaic of 1:20 000 nominal scale derived from the 1966's aerial campaign at scale 1:40 000. The photo mosaic was complemented with some partial land parcel map already existing and individual survey maps when needed. In 1998 a vectorization was performed through an agreement between DNC and the National Directorate of Mining and Geology (Dirección Nacional de Minería y Geología, DINAMIGE) using the local reference system ROU-USAMS. In 2006 a change of 
projection was performed, using the global reference WGS84, UTM Zone 21 South through a new agreement between DNC and the Minister of Cattle, Agriculture and Fishing (Ministerio de Ganadería Agricultura y Pesca, MGAP). After this short summary, it can be stated that the Uruguayan Cadastre is a mixed one, considering that in its creation took part DNC as well as external bodies. For the sake of this paper, its most significant feature is that it has been derived from a photo mosaic and not from the survey maps themselves.

According to Faure Valbi et al., (2010) and Barreto et al., (2010) the resulting land parcel map has a planimetric accuracy at the $95 \%$ confidence level of the order of 200 meters. Such value is deemed too large if one wants to assure interoperability with other cartographies, so an update (using a methodology yet to be defined) is being considered. In this work we will analyze the use of the individual survey maps as the starting point, together with GNSS tracks of the public roads both already available in digital form for the whole country. Afterwards we could experimentally establish the achievable error levels, either considering the planimetry, parcel areas and/or parcel length borders. Such error values might be used as reference for a bidding process if this procedure is selected. Conversely, they can be considered before to either choose or discard the procedure as a whole.

This paper is organized in seven sections. In the next one we will discuss the State of the Art, afterwards the Data and Methods will be described and we will devote a section to analyze the Problems encountered. Then we will present the Results, develop the Conclusions and finally the References will be listed at the end.

\section{State of the Art}

Building a land parcel map is not a new topic. The main motivation for having a land parcel map was the proper definition of taxes and audits, but as time passed new roles have been assigned. Such roles are formulated in initiatives like the National Spatial Data Infrastructures (NSDI) which intends to offer to the government and the general public trustable geographic information, updated and interoperable. This paper is devoted to the last requirement. The surge of NSDI applications made clear that today a significant geometric accuracy update is mandatory if the interoperability requirement is to be met. There is no single way to achieve that; a new dataset could be created from scratch or the existing one could be modified. The principal alternatives might be organized according to the reference used: manually generate it from scratch using an orthoimage as reference (Sandoval, 2004; Balado and López-Vázquez, 2020), apply a mathematical transformation to the legacy land parcel map (Siriba et al., 2012) or even the use of information without geographic reference (Hesse et al., 1990; Tamim, 1992; Tong et al., 2009; Sisman, 2014; 
Cvijetinovic et al., 2015). We have restricted the list to those papers that considered also the accuracy in terms of area.

Sandoval (2004), presented a comparison between a soil cartography at scale 1:50.000 created with a simple photogrammetric procedure and another build as a reference one created with a digital photogrammetric procedure. The differences were presented as absolute values, despite that they stated a relative error in area below 5\% while the planimetric error computed from 150 control points was $68 \mathrm{~m}$. Unfortunately no results at the parcel level were reported but only those at land use classes.

Balado and López-Vázquez (2020) did something similar extracting the apparent cadastre from an orthoimage of $0.50 \mathrm{~m}$ resolution, $3.2 \mathrm{~m}$ planimetric accuracy according to the National Standard for Spatial Data Accuracy (NSSDA hereinafter) (FGDC, 1998). They edited an existing legacy digital cadastre in order to fit it to the image. The relative error for the parcel areas (defined in eq. 1) was proved to have a normal distribution, with mean value $-1.72 \%$ and standard deviation $8.59 \%$. Such figures should be compared with the values for the legacy cadastre, with a mean value of $-0.66 \%$ and standard deviation of $11.25 \%$. According to Uruguayan regulations, while comparing to the existing land base information a new survey map should be rejected for further analysis if its relative discrepancy in area exceeds $5 \%$. Using the legacy digital cartography, only $39.3 \%$ of the survey maps met such requirement, while after the fit with the orthoimage the modified land parcel base accepts $49.7 \%$.

Siriba, et al., (2012) uses for the task both a low accuracy, legacy land parcel map as well as GNSS road tracks, reliable and more accurate. From the former they extract the implicit roads, which are processed to fit to the latter through a spline transformation. To evaluate the resulting accuracy a high resolution orthoimage was used as a reference. Due to some difficulties to identify all the parcel boundaries they grouped them in blocks until the block borders were crisp. They report an improvement (not precisely described) in terms of the areas of $92.8 \%$, but they not disclosed the reference source neither provide figures at the parcel level. The procedure has some contact points to the one to be applied here.

Hesse et al. (1990) compared different techniques used to register scanned maps, from the simplest (rotations, translations, affine transformations, etc.) to more sophisticated ones that considered keeping angles between segments or the declared area of the parcel. They summarized their results in terms of the relative error of the area as well as absolute planar coordinates in a (possibly urban) test case. They concluded that adding the areas or the angles as a restriction offered a significant improvement, but not necessarily both at the same time.

Starting from the survey maps as well, Tamim (1992) did something similar to what is reported here. However, in his case he could not assume that the parcel 
areas were very accurate. After joining together the parcels in a block, he proposed to adjust the corners of the parcels by imposing restrictions, such that all fronts are aligned, right angles are preserved, continuity of the tangents at curved limits are enforced, etc. as well as the parcel area and also control points if they are available. After adding weight coefficients to each restriction the problem can be stated as one of nonlinear least squares. A linearized approximation is used in order to solve it, and a simple case is presented as an example. Unfortunately, this pioneering work has had very little impact on the literature.

Tong et al. (2009) described a complete automatic survey map adjustment procedure considering at the same time the position error as well as area discrepancy, and taking into consideration other restrictions like parallelism between fronts, right angles, etc. The process can be applied to a single survey map or a block. The solution requires to assemble a non-linear system of equations describing area restrictions, points alignment, angles, etc., to derive a first order approximation (i.e. linearize it) and solve the resulting problem through the normal equations. Like the present paper, their work also deals with blocks but of urban areas. In their example the streets are also parcels. The initial relative errors are of the order of a few per cent, but for some small parcel they can exceed $10 \%$.

Sisman (2014) compared different techniques to establish the parameters of the affine transformation to a given map including the Total Least Squares procedure. As a byproduct the author presented the relative error of the parcel areas in a test case, which was below $5 \%$.

Cvijetinovic et al. (2015) also followed a process of synthesis of the land parcel map base starting with survey maps. After comparing the areas derived from field notes with the vectorized one, they found that $94 \%$ of the cases the agreement is better than the $1 \%$.

The goal of this paper is to establish realistic achievable values of attainable accuracy using a particular procedure. There are, however, general criteria which might be worth to consider. Thapa and Bossler (1992) described the typical error values of geographic information, with emphasis in those that arise after capturing the data through secondary processing. After considering drawing errors, heat and humidity dilation and contraction of the media, scanning, vectorization, etc. they conclude that it is reasonable to expect an error between 0.5 and $0.81 \mathrm{~mm}$ a the map scale. For the case we have at hand (land parcel map at nominal scale of 1:40.000) such criteria will establish a lower bound of 20 to $32 \mathrm{~m}$. Notice that such criteria presumes that the original information was on analogous media.

Some Cadastral Agencies specify admissibility criteria in order to accept a new survey map in the system. The Catamarca province Cadastral Agency (Argentina) states tolerances in terms of side length, with different values for urban, suburban or rural areas (Resolution 276-2013). In the same country, the Santa Fe province Ca- 
dastre establishes a similar criteria but expressing the limits in absolute value, ranging from $0.08 \mathrm{~m}$ in urban parcels, $0.15 \mathrm{~m}$ at suburban and $0.5 \mathrm{~m}$ in rural ones (Cap. XIII, Art. 155 of Provincial Decree 1309/2017). The Brazilian technical norm (INCRA, 2013) only establishes absolute tolerances for the rural case, varying from $0.50 \mathrm{~m}$ to 7.50 according to the difficulty for accessing the field point. Boey (1999) summarizes the requirements of the time for Australian states in term of angles, length or locations. For the latter it specifies tolerances of the order of $0.15 \mathrm{~m}$. For lengths they prescribed a model $\mathrm{A}+\mathrm{Bxppm}$, with $\mathrm{A}$ of the order of $1 \mathrm{~cm}$ and $\mathrm{B}$ up to $100 \mathrm{ppm}$. In any case such limits are well below the achievable values according to Thapa and Bossler (1992). It should be mentioned that those countries have a much bigger scale of cadastral maps (e g. Australia between 1:1 000 and 1:5 000, in Argentina between 1:1 000 and 1:5000 in urban areas), which justifies somewhat the need of basic information of higher accuracy.

In Uruguay the Resolution 24/996 (1996) states allowable limits to the geometric discrepancy between the new survey maps and the already registered ones. In particular, parcel area might differ up to $5 \%$ and parcel side lengths up to something between 2 and 5\%, being the larger value for natural limits. There are no provisions for absolute coordinates. A similar criteria is applied in Malaysia (Jeffri et al., 2017) but varying the limit: $5 \%$ for up to 40 ha, $2 \%$ for parcel between 40 and 200 ha and no more than $1 \%$ for parcel larger than 200 ha.

With regard with parcel side lengths, the Uruguayan criteria might be regarded as less strict than in other places. For any rural parcel with one border of more than $25 \mathrm{~m}$, the Uruguayan criteria will accept differences larger than $0.5 \mathrm{~m}$, which in turn is the maximum allowable in Catamarca or Santa Fe. It is not easy to relate the tolerances in area with those of length or position (Chrisman and Yandell, 1988) so we will not compare the regulations in those terms. Finally, and only since 1995, in Uruguay all the new survey maps must include a table with the coordinates of all the vertex of the parcel in an orthogonal, local, arbitrary system, which might obviate the digitalization errors in future digitalization works.

\section{Data and Methods}

This work was motivated by a procedure proposed to the second author by Ing. Agrim. F. Barbato (Barbato, 2014) who suggested to interpret each parcel as a unique and specific entity in the land parcel map, which after joining with its neighbors will belong to a unit. The process will first require a scanning from the original polyester survey map followed by a vectorization of the image plus setting a proper scale. Afterwards, the parcel will be merged and (if deemed necessary) adjusted with neighbors parcels in order to form a block. Finally the unit will be rotated and translated in order to fit within the road network, defined with absolute coordinates. After this quick introduction we will present the details. 
Since in Uruguay the public areas are not recorded in the land parcel map, the joining process between parcels will stop at roads, rivers, etc., as happens in other countries (Tamim, 1992; Siriba et al., 2012). In this work we will denote as "block" the simply connected set of parcels which share at least one border with the others and which external limit is either a road, a river, or an international boundary. The rural survey maps (nearly 250000 in Uruguay) are scanned but not vectorized, a task that was carried out in this project for the study zone. Because they do not have absolute coordinates we will register it to a network of GNSS road and highways tracks, available for the whole country.

The abovementioned vectorization was not automatic, so each parcel was scaled, rotated and eventually slightly adjusted in order to fit with its neighbors. The scale of the survey map was defined considering at least one length dimension explicitly stated in the document (usually the largest available). Afterwards, in the CAD environment, it was fairly easy to compute the area of the resulting polygon, and the discrepancy against the declared area (supplied by the surveyor and deemed exact) provided a first measure of geometric accuracy.

This pilot test used the images of the survey maps stored at the Topography Directorate of the Ministry of Transportation and Public Works (Dirección Nacional de Topografía del Ministerio de Transporte y Obras Públicas). They were produced after microfilming the original polyester survey map and scanning later from the microfilm. As interim information we used the legacy land parcel map of the Canelones county available from DNC. The GNSS tracks for such county was generated by the UNA-ONU project (2009) and downloaded from the NSDI of Uruguay. We want to report the accuracy not only in area terms, but also in planimetry. To provide absolute reference for the planimetric error an orthoimage of $0.50 \mathrm{~m}$ resolution, $3.2 \mathrm{~m}$ accuracy at the $95 \%$ confidence level was provided by the Military Geographic Institute (IGM) through its Open Data Initiative.

To have a small but representative test case we selected a block bounded by roads with as many parcels as possible and with survey maps available, all within the region covered by the orthoimage. The selected study area of $19 \mathrm{~km}^{2}$ belongs to the rural area of the Canelones county, and is located between the Solís Grande and Solís Chico rivers, as sketched in Figure 1. It is composed of 74 parcels, with varying sizes between 0.9 and 138.3 ha.

As a first step we located and downloaded the images of each of the survey maps. The second step was to vectorize the parcel boundaries using a CAD tool as presented in Figure 2. We used a scale factor defined by a single segment of the image with stated length. Finally, after closing the polygon, the area value (denoted as Vectorized Area hereinafter) was computed. When the border lengths were available we also recorded both, at image and at the polygon, for further processing. Once the survey maps were vectorized we proceed to assemble all of them in a similar process than to form a puzzle, joining the parcels with its neighbors using just rotation and translation tools. When the borders did not fit, we performed a small manual edition trying not to disturb the rest of the geometry. Thus, the puzzle 
assembling was not achieved strictly through pure isometric transformations. Unlike others did (Tamim, 1992; Tong et al., 2005; 2009; Siriba et al., 2012, etc.) all the process was manual. In Figure 3 the final product is shown.

After that, we exported this block from AutoCAD $2010 * \mathrm{dwg}$ format to a GIS ArcMap 10.3, where the GNSS tracks were available. Once represented together, we manually registered the block fitting it within the envelope of the GNSS tracks thus giving absolute coordinates to the dataset.

The planimetric quality control required the use of the orthoimage, which was used as a reference. We selected those corners of the parcels that were easily identifiable in the image, and we measure and store its coordinates in the image, in the new land parcel map and in the legacy one. Such values were used for the NSSDA computations.

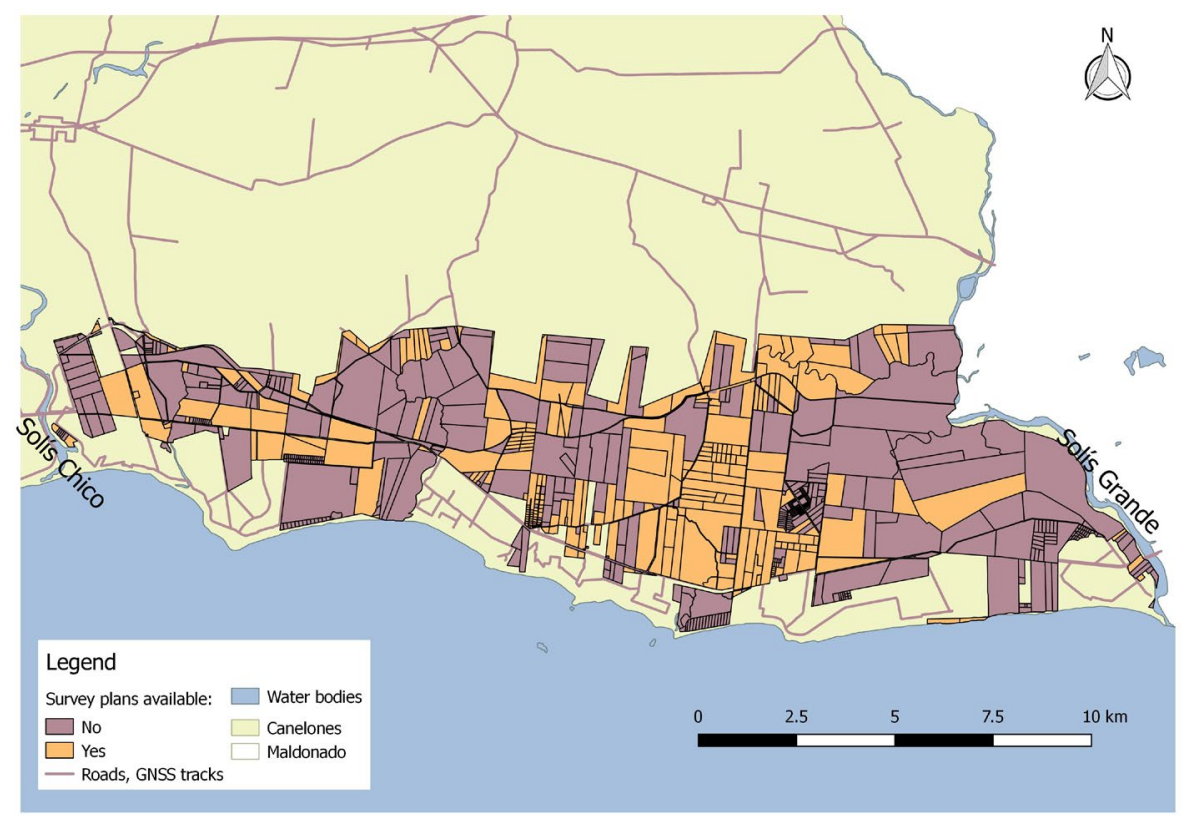

Figure 1. Location of the test zone.

Source: own elaboration.

For the area computations we adopted as a reference the value declared by the surveyor, number which is both mentioned in the image as text and stored as attribute in the database. We disregarded any correction of the computed areas due to the cartographic projection, a decision that will be justified later. We analyzed each step of the process and computed the relative error of the intermediate areas for 
each. Taken into consideration the highly variable parcel areas, we used the relative error as the relevant metric. Such value is defined in (1); notice that it has a sign.

$$
e=\frac{(\text { computed_area }- \text { declared_area })}{\text { declared_area }} * 100
$$

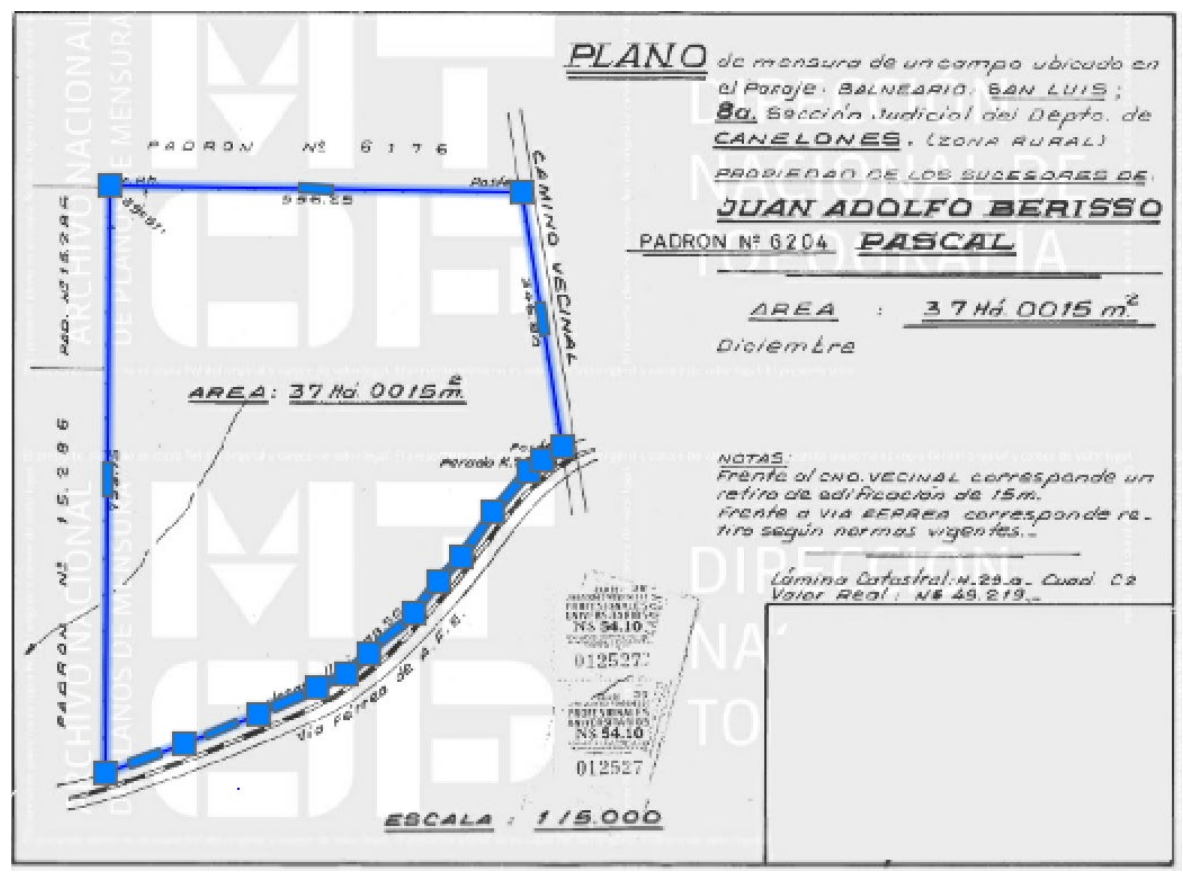

Figure 2. Illustrating the vectorization process. Notice that the declared area is explicitly mentioned (with text) in the survey map, as well as some lengths close to the parcel boundaries.

Source: own elaboration.

In summary, and in terms of parcel areas, there are three relative errors considered in this paper. After the first vectorization plus scaling of each parcel we can compare the computed area to the declared one. To evaluate the block assembling process we have the final land parcel map to use. Since the legacy one is also available, we computed its relative error as well. When data was available, we also computed the relative discrepancies in terms of the length of the parcel boundaries. Finally, we performed the standard planimetric accuracy computation using the orthoimage as a reference. It should be stressed that no field work was needed for this paper. 


\section{Problems encountered}

In some parcels there were large discrepancies between the land parcel map and its survey map. One possible explanation is missing data updates like, for example, some subdivision or fusion of the parcel that was not recorded in the dataset. There might be some other reasons which we could safely assume that are not related with the geometry neither with the vectorization process. So, to have more reliable conclusions, we arbitrarily remove from consideration those cases of parcels which exceed $25 \%$ the relative error of the area. The remaining population has 64 parcels, with a relative error that follows a normal distribution according to the Kolmogorov test. On principle we could estimate raw averages and sample standard deviation to estimate its parameters. However, since we suspect that there are still some extra outliers present, we applied the MCD procedure (Rousseeuw and van Zomeren, 1990) which renders values equivalent to the traditional estimate of the first and second moments of the distribution (namely, mean and standard deviation) but immune to the existence of outliers. As a byproduct it generates a reliable Inlier/Outlier classification. Afterwards the parameters of the normal distribution (mean and standard deviation) were computed using the Inlier subsample, and they are the ones to be presented here.

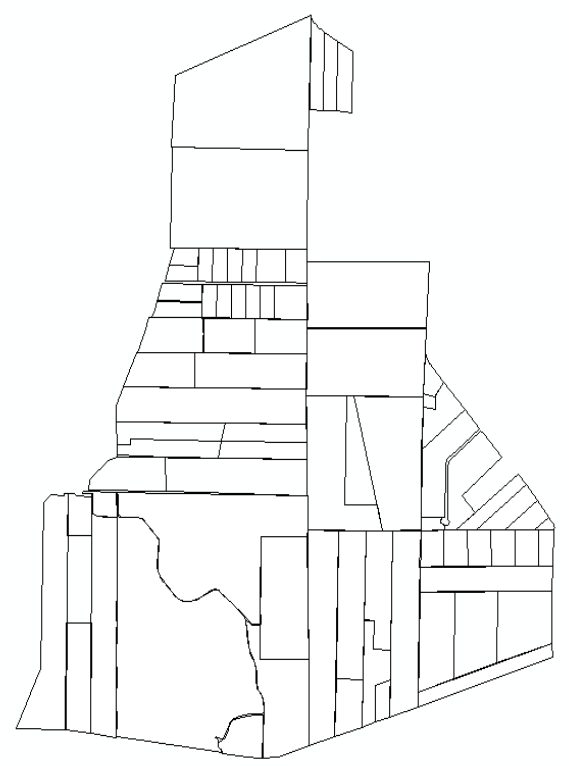

Figure 3. Sketch of the final block.

Source: own elaboration. 
Some practical problems to be described now here might not be significant elsewhere, but we feel that they should be mentioned. At the moment of downloading the survey maps some issues appeared, like having the same parcel number attributed to two different parcels, or realizing that some parcel had changed its number without clear notice. To solve the first issue, the DNC's geoportal proved to be a valid tool because it shows the survey map using its number. For the second case we had to dig into earlier survey maps looking in the image itself and then try to find either the owner or the old parcel number. However, despite our efforts some cases could not be resolved.

Due to this fact we were unable to include all the parcels and to perform the area computations as originally planned. In addition, no second block could be found within the region covered by the orthoimage, so we have had no other choice than to continue despite the holes.

Despite the survey maps had a printed scale, its usefulness is somewhat doubtful because we could not discern the original size of the polyester media after the scanning process. That is the reason behind the use a de-facto scaling with an explicit length visible in the survey map image.

As soon as we started forming the puzzle we noticed that the parcels do not fit always exactly with its neighbors. There were cases of slight overlapping and also of interstices, so small adjustments were carried out in order to properly share the boundaries. Through a purely subjective process, we altered only the minimum number of corners in order to keep as much as possible other dimensions of the parcel.

We are aware that there exist more sophisticated and objective approaches to fit a puzzle while keeping the area values, like those presented by Hesse et al. (1990); Tamim (1992); Tong et al., (2005), and Tong et al., (2009). However, their code was not readily available for our project. Due to the time and resources restrictions and considering our goal, we were satisfied by just applying manually some minor adjustments.

\section{Results}

\section{Relative error of parcel area and lengths}

After building the puzzle and giving global coordinates to the block we have got the proposed cartography as depicted by Figure 3. Then we computed the final area of each parcel, and once the outliers were considered, we fitted the inliers to a normal distribution. The inliers average was $0.10 \%$ while its standard deviation was $3.51 \%$. The legacy land parcel map showed that the inliers also belong to a normal distribution with average $-4.68 \%$ and standard deviation $8.24 \%$ (see Table 1). Notice the drastic reduction (to less than a half) of the standard deviation and also the clear bias reduction, but also notice that the final values are still somewhat large. 
The land parcel map accuracy is usually reported in terms of its planimetric accuracy. Its value is expected to diminish after a cartographic improvement process. In the specific case of Uruguay, the DNC rules provide another indirect metric to quantify the improvement. According with the rules of Resolution 24/996 a new survey map that differs with the prior information more than $5 \%$ in the relative error of its area will require further explanations. To simplify the situation let's assume that the already existing survey maps are presented again to DNC. After comparing against the current land parcel map it can be seen that some of them will be accepted and some rejected. In our dataset only 17 parcels (39.5\% of the 43 declared as Inliers) could be accepted. Even though our test is based in a very small sample, this acceptance rate is comparable with the one for the whole rural Uruguay (nearly 250.000 parcels) which accounts for $35.5 \%$. After building the proposed cadastre with our procedure, the number of acceptable parcels grows up to $41(82.0 \%$ of the 50 Inliers), which is deemed as an important improvement yet still far from the ideal case that should accept $100 \%$. If instead of areas we consider the acceptance criteria for the relative error of lengths (bounded by $2 \%$ in Uruguay) the improvement of the process is still more dramatic: in the legacy land parcel map base just 1 out of 14 parcels can be accepted (7.1\%), while in the proposed one we can accept 7 (17.9\% of a set of 39 inliers) (see Table 2). In this case we defined as inlier any parcel which maximum relative error in side length was below $10 \%$.

Table 1

Results in terms of parcel area relative error using the MCD criteria to classify the Inliers

\begin{tabular}{ccccc}
\hline Stage & Inliers & Average & Standard deviation & $<5 \%$ \\
\hline Present cadastre & 43 & -4.68 & 8.24 & 39.5 \\
After vectorization & 50 & 0.28 & 2.55 & 92.0 \\
Proposed cadastre & 50 & 0.10 & 3.51 & 82.0 \\
\hline
\end{tabular}

Source: own elaboration.

It is worth mentioning that, in the case of the parcel lengths, the dataset is very irregular. Some of the survey maps lacks from explicit information on some lengths, or it simply missing at all, because such information has been mandatory only after 1995. This was not the situation with the declared parcel area, which has been always required. Thus, and considering also the small sample, great care 
should be taken at interpreting our results in terms of side length. The finding of a positive correlation between the improvement in area and length is consistent with the results of Hesse et al. (1990).

Table 2

Results in terms of the length relative errors using the $10 \%$ upper limit to define the Inliers

\begin{tabular}{ccccc}
\hline Stage & Inliers & median (\%) & quartil $75 \%$ & $<2 \%$ \\
\hline Present cadastre & 14 & 15.0 & 24.2 & 7.1 \\
After vectorization & 41 & 3.1 & 5.4 & 29.3 \\
Proposed cadastre & 39 & 4.4 & 8.2 & 17.9 \\
\hline
\end{tabular}

Source: own elaboration.

\section{Planimetric accuracy}

The main motivation to update the land parcel map was directly related with this metric. Despite the present regulations of DNC in Uruguay do not prescribe any accuracy for the absolute coordinates there exist others that do, so it is fit to quantify it. We used a high resolution orthoimage supplied by IGM to identify corners of the parcels in the image used as true values. Following Siriba et al. (2012) we collected also its coordinates in both present and proposed land parcel map (see Table 3 and Figure 4).

As a widely accepted and objective test of accuracy we applied the NSSDA standard (FGDC, 1998) using a set of 34 corners either in the border or interior to the block. On a case by case basis, and always following the standard, some outliers were detected and removed for the computations. The result of the planimetric error to the $95 \%$ level of confidence was $276.1 \mathrm{~m}$ for the legacy land parcel map. It is a value comparable with the ones reported by Barreto et al. (2010) or by Faure Valbi et al. (2010) (namely, $200 \mathrm{~m}$ ) but not as low as the one reported by López-Vázquez, (2014) of $136 \mathrm{~m}$. For the proposed cadastre the result was $53.8 \mathrm{~m}$. It should be stressed that the accuracy of the orthoimage was $3.2 \mathrm{~m}$, so according to FGDC (1998) it can be used as a reference source of higher accuracy. 
Table 3

Coordinates of control points in the orthoimage, original cadastre (CDP) and proposed cadastre (puzzle). We highlight the components of those points which were later classified as outliers and removed from calculations

\begin{tabular}{|c|c|c|c|c|c|c|}
\hline Point & $X$ (ortho) & $Y$ (ortho) & $X(C D P)$ & $Y(C D P)$ & $X(p u z z l e)$ & $Y($ puzzle $)$ \\
\hline $\mathrm{a}$ & 635464.25 & 6154666.90 & 635547.82 & 6154511.00 & 635453.00 & 6154649.54 \\
\hline $\mathrm{b}$ & 636620.41 & 6154944.90 & 63669 & 6154788.79 & .24 & 978.88 \\
\hline $\mathrm{c}$ & 637579.20 & 6154102.84 & 637659.15 & 6153959.76 & 637596.01 & 6154070.73 \\
\hline $\mathrm{d}$ & 637340.38 & 6152374.56 & 637433.36 & 6152237.63 & 637290.79 & 6152368.49 \\
\hline $\mathrm{e}$ & 638202.22 & 6150992.02 & 638330.35 & 6150882.92 & 638208.67 & 6151016.20 \\
\hline $\mathrm{f}$ & 638066.98 & 6150001.82 & 638223.62 & 6150012.61 & 638099.37 & 6150025.24 \\
\hline g & 635598.80 & 6149548.56 & 635719.44 & 6149485.10 & 635639.95 & 6149531.11 \\
\hline $\mathrm{h}$ & 633866.30 & 6149976.21 & 633970.63 & 6149934.62 & 633626.76 & 6149966.96 \\
\hline $\mathrm{i}$ & 634115.18 & 6150397.70 & 634165.63 & 6150302.03 & 633883.22 & 6150391.19 \\
\hline $\mathrm{j}$ & 634240.53 & 6151623.50 & 634286.73 & 6151537.70 & 634035.54 & 6151617.19 \\
\hline $\mathrm{k}$ & 634693.10 & 6151875.21 & 634814.25 & 6151823.01 & 634675.56 & 6151904.14 \\
\hline 1 & 634744.34 & 6152273.32 & 634847.09 & 6152223.26 & 634733.70 & 6152316.96 \\
\hline $\mathrm{m}$ & 635301.50 & 6153447.01 & 635398.21 & 6153233.14 & 635273.46 & 6153386.72 \\
\hline 0 & 636213.69 & 6151180.06 & 636339.71 & 6151053.77 & 636182.88 & 6151177.64 \\
\hline 1 & 636200.68 & 6151139.74 & 636318.93 & 6151045.77 & 636178.26 & 6151133.20 \\
\hline 2 & 636290.74 & 6151943.81 & 636397.95 & 6151853.74 & 636260.44 & 6151959.81 \\
\hline 3 & 636380.80 & 6152674.28 & 636485.80 & 6152527.62 & 636337.56 & 6152665.05 \\
\hline 4 & 636433.90 & 6153156.58 & 636539.62 & 6152999.42 & 636391.44 & 6153159.23 \\
\hline 5 & 636517.58 & 6153962.51 & 636606.45 & 6153828.03 & 636483.57 & 6153981.10 \\
\hline 6 & 636892.60 & 6154144.47 & 636998.43 & 6153997.33 & 636876.04 & 6154222.94 \\
\hline 7 & 637054.26 & 6154124.10 & 637268.91 & 6153961.10 & 637199.88 & 6154130.21 \\
\hline 8 & 636404.27 & 6152976.30 & 636504.86 & 6152861.14 & 636376.24 & 6153002.60 \\
\hline 9 & 635493.04 & 6152571.75 & 635600.35 & 6152423.70 & 635466.15 & 6152583.16 \\
\hline 10 & 635426.05 & 6152575.19 & 635600.35 & 6152423.70 & 635395.73 & 6152591.82 \\
\hline 11 & 635587.76 & 6152039.50 & 635739.45 & 6151943.50 & 635594.72 & 6152038.67 \\
\hline 12 & 635532.33 & 6151786.81 & 635646.91 & 6151690.92 & 635501.42 & 6151789.07 \\
\hline 13 & 634660.76 & 6151461.01 & 634736.33 & 6151373.15 & 634649.89 & 6151443.65 \\
\hline 14 & 637563.31 & 6151020.63 & 637527.99 & 6150922.97 & 637575.08 & 6151031.55 \\
\hline 15 & 637800.40 & 6150999.45 & 637742.63 & 6150898.42 & 637804.05 & 6151009.72 \\
\hline 16 & 637704.73 & 6150538.84 & 637850.55 & 6150464.08 & 637702.90 & 6150560.62 \\
\hline
\end{tabular}


Continuated Table 3

\begin{tabular}{lllllll}
\hline 17 & 636953.41 & 6149875.21 & 637102.64 & 6149794.74 & 636963.20 & 6149885.51 \\
18 & 636096.83 & 6150230.20 & 636210.52 & 6150116.17 & 636089.18 & 6150223.39 \\
19 & 635701.44 & 6150275.45 & 635816.21 & 6150152.01 & 635694.50 & 6150264.96 \\
20 & 636325.86 & 6152181.08 & 636447.02 & 6152100.63 & 636280.08 & 6152175.72 \\
\hline
\end{tabular}

Source: own elaboration

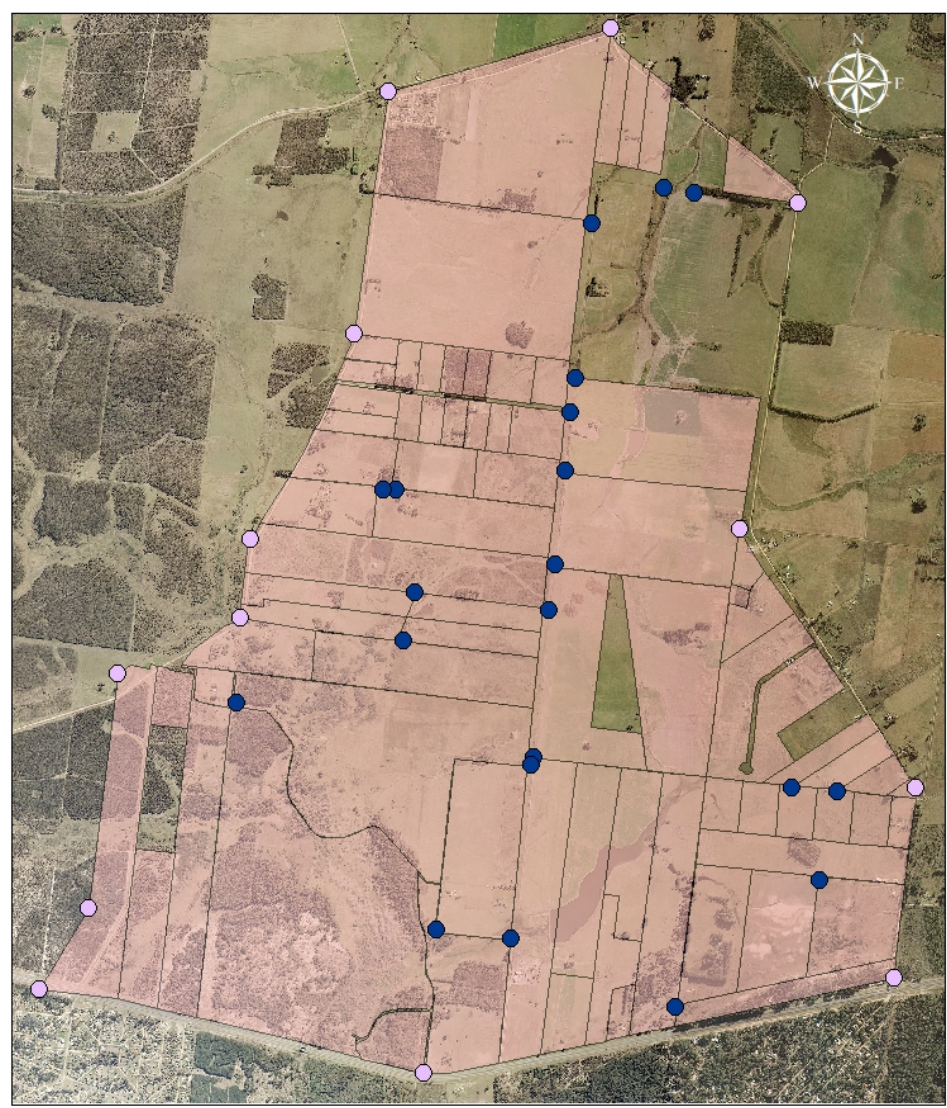

\section{Legend}

- Inner points

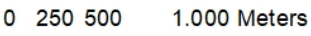

- Outer points

Proposed cadastre

Orthoimage: RGB

Figure 4. Proposed cadastre presented on top of the reference orthoimage. We highlight those corners used for the planimetric accuracy evaluation.

Source: own elaboration. 


\section{Conclusions}

In the context of a NSDI the availability of a geometrically interoperable land parcel map is very important. Where it exists but is not interoperable, it can be considered to modify it thus retaining all the topology information as well as the attributes. If for some reason such option is discarded, the requested land parcel map could be created by a) new field work b) using orthoimagery or c) assembling the individual survey maps like a puzzle. In this work we tested the last option, in order to estimate what accuracy can be achieved with the procedure and use such values eventually in a future bidding process. Unlike the common practice in other countries and considering the rules applicable in Uruguay, we measured the geometric improvement not only in terms of planimetric accuracy but also using the relative error of parcel area as well as lengths included in the survey maps. The consideration of the parcel area as a non-standard metric can be justified by the own goals of the DNC. In Uruguay the parcel area it is not extracted from the geometry of the survey map but explicitly declared by the surveyor after direct computations using field measurements. Its value is deemed to be very accurate.

The disagreement between area computed from the scanned version of the survey map and its declared value was expected to be small, but it was not. The relative error has a normal distribution, with a mean value of $0.20 \%$ and $2.55 \%$ of standard deviation. We found no conclusive explanation for that, and in any case it is outside the scope of this research. The survey maps were made by different surveyors in different moments and with different instruments and computation techniques, so we believe that there is statistical independence in the area values errors. In Uruguay the field book need not to be stored so there is no practical way to check the computations. Regarding the vectorization step, since 1995 in Uruguay it is mandatory to include in the survey maps a printed table with coordinates of every corner, data which in the future might help avoiding the need of vectorization of polygons going straight to the vector version. In such case the declared area and the computed area are likely to coincide. After more than 20 years with the new rules only $10 \%$ of the existing survey maps were produced in the period, thus limiting our options in practice.

There are different ways to quantify the improvement of the proposed new cadastre with respect to the available and somewhat inaccurate one. The relative area error has a normal distribution in both cases, but in the former has a standard deviation of $3.51 \%$ which is less than half the one we have now $(8.34 \%)$, thus showing a substantial drop. However, it cannot decrease further because the baseline using the individual survey maps showed a standard deviation of $2.55 \%$. The conclusion is that the bidding requirements in terms of standard deviation of the relative error of the parcel areas should be higher than $2.55 \%$ provided the stored image of the original survey map is used as the base document. 
A second measure of geometric accuracy is the planimetric one, which is crucial to assure interoperability with other datasets. There are no Uruguayan regulations to consider. Once we applied the NSSDA standard to quantify it we realize that the new value could be $53.8 \mathrm{~m}$ while the present cadastre has an accuracy of $276.1 \mathrm{~m}$, a value consistent with other independent evaluations of the same land parcel map for other regions in the country. Despite a remarkable improvement, the new value is still far of what is required by regional and international standards, thus leading to the conclusion that with this procedure and the available survey maps the intended goal could not be achieved. Absolute accuracy of the product is affected by the accuracy of road centerlines, which are not a well defined part of the parcels neither the block. To improve the former fairly detailed and precise GNSS data of the fences surrounding the block should be used instead of the data available for this test.

Considering the acceptance criteria for new survey maps at DNC, if the current legacy land parcel map is taken as a reference just $39.5 \%$ of the original survey maps could be accepted if presented again today. I the proposed adjusted cadastre is used instead, such acceptation rate might grow to $82.0 \%$.

As an innovative characteristic of this work we stress that the accuracy in the parcel areas should be included jointly with other standard planimetric accuracy statements. The parcel area has important roles on its own, both economic and legal.

\section{Acknowledgements}

This work could not have been done without the support of the Director and personnel of the Geodesy and Topography Division and the Restitution and Photogrammetry Division of the Military Geographic Institute of Uruguay. We want to mention also the support of Mr. Ing. Agrim. Hebenor Bermúdez, who provided references and valuable advice for the task. We acknowledge the financial support to the first author from the PEDECIBA-Geociencias program.

\section{References}

Balado, I. and López-Vázquez, C. (2020). “Admissible relative errors of the parcel area of a land parcel map base created using an orthoimage as a reference", Revista Cartográfica, núm. 100, 15 pp. (Accepted)

Barbato, F. (2014). Personal communication.

Barreto, L.; Bermúdez, H.; Blanco, D.; Di Leoni, A.; Faure, J.; Méndez Baíllo, R.; Pérez Rodino, R.; Sánchez, M.; Striewe Dieste, E.M. (2010). "Evaluación de la Calidad de la Exactitud Geométrica Absoluta del Parcelario Rural Digital Vectorial del Departamento de Lavalleja”, Agrimensura, vol. 44, pp. 2-7. 
Boey, S.S. (1999). "A model for establishing the Legal Traceability of GPS Measurements for Cadastral Surveying in Australia", Ph.D. Thesis, University of New South Wales, Australia, UNISURV REPORT S-55, 205 pp.

Chrisman, N.R. and Yandell, B.S. (1988). "Effects of Point Error on Area Calculations: A Statistical Model", Surveying and Mapping, vol. 48, pp. 241-249.

Cvijetinovic, Z.; Avramovic, M. and Mihajlovic, D. (2015). "Digital cadastral map as foundation of coordinate based cadastre of Serbia", in Survey Review, vol. 47, no. 343 , pp. 241-255.

Decreto 318/995 (1995). "Registración de Firma y Título Profesional en la Dirección General del Catastro Nacional. Planos de Mensura", Uruguay, $<$ http://cort.as/-1694>, consultado el 22 de enero de 2018.

Decreto Provincial 1309/2017 (2017). "Normas para la confección y Registración de Planos de Mensura", Gobierno de la Provincia de Santa Fe, Argentina, $<$ http://cort.as/-1po5 >, consultado el 22 de enero de 2018.

Faure Valbi, J.; Blanco, D.; Bermúdez, H.; Méndez-Baíllo, R.; Barreto, L. y Striewe, E. (2010). "Evaluación de la calidad de la exactitud geométrica absoluta del parcelario rural digital vectorial del Departamento de Lavalleja", Proyecto de Instituto de Agrimensura, Facultad de Ingeniería, Universidad de la República (no publicado), $37 \mathrm{pp}$.

FGDC (1998), "Geospatial Positioning Accuracy Standards Part 3: National Standard for Spatial Data Accuracy", Federal Geographic Data Committee, FGDCSTD-007.3-1998, 28 pp.

Hesse, W.J.; Benwell, G.L. and Williamson, I.P. (1990), "Optimising, maintaining and updating the spatial accuracy of digital cadastral data bases", Australian Surveyor, vol. 35, no. 2, pp. 109-119.

INCRA (2013) "Norma técnica para georreferenciamento de imóveis rurais", Instituto Nacional de Colonização e Reforma Agrária, 4 pp.

Jeffri, M., Hisham, O. and Joanes, J. (2017). "Effectiveness of Localised Adjustment in Strengtening National digital Cadastre Database", submitted to Jurnal Teknologi, <www.jurnalteknologi.utm.my>, 9 pp.

Resolución 24/996 (1996). "Uniformización de normas de planos de mensura, copias, formatos, escalas.”, Dirección Nacional de Catastro, Uruguay, $<\mathrm{http}: / /$ cort.as/-1iPz>, consultado el 22 de enero de 2018.

Resolución 276-2013 (2013). "Verificación de subsistencia del Estado Parcelario", Administración General del Catastro, provincia de Catamarca, Argentina, $<$ http://cort.as/-1pn8>, consultado el 22 de enero de 2018.

Rousseeuw, P.J. and van Zomeren, B.C. (1990), "Unmasking Multivariate Outliers and Leverage Points", Journal of the American Statistical Association, vol. 85, pp. 633-639. 
Sandoval, V. (2004). “Cartografía elaborada con un método fotogramétrico simple versus un método digital (Softcopy-Fotogrametría)", BOSQUE, vol. 25, no. 1, pp. 87-94.

Siriba, D.N.; Dalyot, S. and Sester, M. (2012). "Geometric quality enhancement of legacy graphical cadastral datasets through thin plate splines transformation", Survey Review, vol. 44, no. 325, no. 91-101.

Sisman, Y. (2014). "Coordinate transformation of cadastral maps using different adjustment methods", Journal of the Chinese Institute of Engineers, vol. 37, no. 7, pp. 869-882.

Tamim, N.J. (1992). "A methodology to create a digital cadastral overlay through upgrading digitised cadastral data", $\mathrm{PhD}$ thesis, Ohio State University, $147 \mathrm{pp}$.

Thapa, K. and Bossler, J. (1992). "Accuracy of spatial data used in geographical information systems", Photogrammetric Engineering and Remote Sensing, no. 58, pp. 835-841.

Tong, X.H., Shi, W.Z. and Liu, D.J. (2005). "A least squares-based method for adjusting the boundaries of area object", Photogrammetric Engineering and Remote Sensing, vol. 71, pp. 189-195.

Tong, X.H., Shi, W.Z. and Liu, D.J., (2009), "Introducing scale parameters for adjusting area objects in GIS based on least squares and variance component estimation", International Journal of Geographical Information Science, vol. 23, no. 11, pp. 1413-1432.

UNA-ONU (2009). “'Unidos en la acción’ Proyecto conjunto C. Desarrollo de instrumentos para el monitoreo ambiental y territorial", $<$ http://cort.as/-8Syf $>$, consultado el 22 de enero de 2018. 